\title{
THE COMPUTATION OF THE NONABELIAN TENSOR PRODUCT OF GYGLIC GROUPS OF ORDER $\boldsymbol{p}^{2}$
}

\author{
MOHD SHAM MOHAMAD ${ }^{1}$, NOR HANIZA SARMIN ${ }^{2 *}$ \\ NOR MUHAINIAH MOHD ALI ${ }^{3} \&$ LUISE-CHARLOTTE KAPPE ${ }^{4}$
}

\begin{abstract}
Let $G$ and $H$ be groups which act on each other and each of which acts on itself by conjugation, then the actions are compatible if ${ }^{\left({ }^{g} h\right)} g^{\prime}={ }^{g}\left({ }^{h}\left(g^{g^{-1}} g^{\prime}\right)\right)$ and ${ }^{\left({ }^{h} g\right)} h^{\prime}={ }^{h}\left({ }^{g}\left(h^{h^{-1}} h^{\prime}\right)\right)$ for $g, g^{\prime} \in G$ and $h, h^{\prime} \in H$. Compatible actions play a very important role in determining the nonabelian tensor product. The nonabelian tensor product, $G \otimes H$, was introduced by Brown and Loday in 1984. The nonabelian tensor product is the group generated by $g \otimes h$ with two relations $\quad g g^{\prime} \otimes h=\left({ }^{g} g^{\prime} \otimes{ }^{g} h\right)(g \otimes h) \quad$ and $\quad g \otimes h h^{\prime}=(g \otimes h)\left({ }^{h} g \otimes{ }^{h} h^{\prime}\right) \quad$ for $\quad g, g^{\prime} \in G \quad$ and $h, h^{\prime} \in H$, where $G$ and $H$ act on each other in a compatible fashion and act on themselves by conjugation. In 1987, Brown et al. gave an open problem in determining whether the tensor product of two cyclic groups is cyclic. Visscher in 1998 has shown that the nonabelian tensor product is not necessarily cyclic, but he only focused on the case of cyclic groups of 2-power order where the action is of order two. In this paper, the compatibility and the nonabelian tensor product of cyclic groups of order $p^{2}$ with the actions of order $p$ are determined.
\end{abstract}

Keywords: Groups; cyclic group; compatible action; nonabelian tensor product

Abstrak. Katalah $G$ dan $H$ dua kumpulan yang bertindak ke atas satu sama lain dan masingmasing bertindak ke atasnya sendiri secara konjugasi, maka tindakan tersebut adalah serasi jika ${ }^{\left({ }^{g} h\right)} g^{\prime}={ }^{g}\left({ }^{h}\left(\left(^{g^{-1}} g^{\prime}\right)\right)\right.$ and ${ }^{\left({ }^{h} g\right)} h^{\prime}={ }^{h}\left({ }^{g}\left({ }^{h^{-1}} h^{\prime}\right)\right)$ for $g, g^{\prime} \in G$ and $h, h^{\prime} \in H$. Keserasian tindakan adalah penting dalam penentuan hasil darab tensor tak abelan. Hasil darab tensor tak abelan, $G \otimes H$, telah diperkenalkan oleh Brown dan Loday pada tahun 1984. Hasil darab tensor tak abelan adalah kumpulan yang dijana oleh $g \otimes h$ dengan dua hubungan $g g^{\prime} \otimes h=\left({ }^{g} g^{\prime} \otimes{ }^{g} h\right)(g \otimes h)$

Department of Mathematical Sciences, Faculty of Science, Universiti Teknologi Malaysia, 81310 UTM Johor Bahru, Johor Darul Takzim, Malaysia

${ }^{2 \times 3}$ Department of Mathematical Sciiences, Faculty of Science and Ibnu Sina Institute for Fundamental Science Studies, Universiti Teknologi Malaysia, 81310 UTM Johor Bahru, Johor Darul Takzim, Malaysia

4 Department of Mathematical Sciences, State University of New York at Binghamton, Binghamton, NY 13902-6000, USA

* Corresponding author: nhs@utm.my 
dan $g \otimes h h^{\prime}=(g \otimes h)\left({ }^{h} g \otimes{ }^{h} h^{\prime}\right)$ bagi $g, g^{\prime} \in G$ dan $h, h^{\prime} \in H$ dengan $G$ dan $H$ bertindak antara satu sama lain dalam tindakan yang serasi dan bertindak ke atas mereka sendiri dengan konjugasi. Pada tahun 1987, Brown dan rakan-rakan memberikan masalah terbuka dalam menentukan sama ada hasil darab tensor tak abelan dari dua kumpulan kitaran adalah juga kumpulan kitaran. Visscher pada tahun 1998 telah membuktikan bahawa hasil darab tensor tak abelan tidak semestinya kumpulan kitaran, tetapi kajian beliau hanya difokuskan kepada kumpulan kitaran berperingkat kuasa bagi dua dengan tindakannya berperingkat dua. Dalam makalah ini, keserasian dan hasil darab tensor tak abelan berperingkat $p^{2}$ dengan tindakan berperingkat $p$ ditentukan.

Kata kunci: Kumpulan; kumpulan kitaran; tindakan serasi; hasil darab tensor tak abelan

\subsection{INTRODUCTION}

The nonabelian tensor product, $G \otimes H$, for groups $G$ and $H$ was originated in connection with a generalized Van Kampen Theorem and its construction has its origins in the algebraic K-theory and in homotopy theory. It was introduced by Brown and Loday in [1]. It is defined for a pair of groups which act on each other provided the actions satisfy the compatibility conditions. A compatible action between two groups is defined as follows:

Definition 1.1. [2] (Compatible Actions) Let $G$ and $H$ be groups which act on each other and on themselves by conjugation. These mutual actions are said to be compatible if

$$
{ }^{\left({ }^{g} h\right)} g^{\prime}={ }^{g}\left({ }^{h}\left({ }^{g^{-1}} g^{\prime}\right)\right) \text { and }{ }^{\left({ }^{h} g\right)} h^{\prime}={ }^{h}\left({ }^{g}\left({ }^{h^{-1}} h^{\prime}\right)\right)
$$

for all $g, g^{\prime} \in G$ and $h, h^{\prime} \in H$.

Now, if $G$ and $H$ are groups which act compatibly on each other, then the definition of the nonabelian tensor products of groups $G$ and $H, G \otimes H$, is given as follows:

Definition 1.2. [2] (Nonabelian Tensor Product) If $G$ and $H$ are groups which act compatibly on each other, then the nonabelian tensor product $G \otimes H$ is the group generated by the symbols $g \otimes h$ for all $g \in G$ and $h \in H$ with relations

$$
g g^{\prime} \otimes h=\left({ }^{g} g{ }^{\prime} \otimes{ }^{g} h\right)(g \otimes h)
$$




$$
g \otimes h h^{\prime}=(g \otimes h)\left({ }^{h} g \otimes{ }^{h} h{ }^{\prime}\right)
$$

for all $g, g^{\prime} \in G$ and $h, h^{\prime} \in H$.

Starting with the paper of Brown et al. [3], many researchers had studied group theoretical aspects of nonabelian tensor products extensively.

When the groups $G$ and $H$ are the same, the nonabelian tensor product becomes the nonabelian tensor square. It is interesting to check the compatible conditions when calculating the tensor product since the groups are not the same or when the actions are nontrivial. Ellis and McDermott [4] had done this but specifically for quaternion group of order 32. Visscher [5] in 1998 had provided necessary and sufficient conditions for a pair of cyclic groups to act compatibly. He gave complete compatible conditions when one of the actions is trivial or both actions are trivial in cyclic groups of $p$-power order. In this paper, we give a new necessary and sufficient condition for a pair of cyclic groups of $p$-power order to act compatibly.

Brown and Loday already established in [2] that the tensor square, $G \otimes G$, is finite for a finite group $G$. Then Ellis [6] extended the results for tensor products. In addition he showed that the tensor product $G \otimes H$ is of $p$-power order if $G$ and $H$ are of $p$-power order. McDermott [4] computed the nonabelian tensor product, $G \otimes H$ when $G$ is a $p$-group and $H$ is a $q$-group, where $p$ and $q$ are primes. However, he just concentrated on the bound on the order of $G \otimes H$ and give some results on that case. Visscher [5] continued the study on the tensor product of $p$-power order and specifically to cyclic groups. He computed some of the tensor product of cyclic group of $p$-power order and gave a complete classification of all nonabelian tensor product of cyclic groups of 2-power order with mutual nontrivial actions of order two.

This paper is focused on the determination of the cyclicness of the nonabelian tensor product of cyclic groups focusing on cyclic groups of order $p^{2}$, where $p$ an odd prime and when both actions have order $p$. 


\subsection{SOME PREPARATORY RESULTS}

The nonabelian tensor product $G \otimes H$ is defined only if $G$ and $H$ act on each other in such way that the actions satisfy certain compatibility condition. An action of a group $G$ on a group $H$ is defined in the following:

Definition 2.1. [5] Let $G$ and $H$ be groups. An action of $G$ on $H$ is a mapping, $\Phi: G \rightarrow \operatorname{End}(H)$ such that $\Phi\left(g g^{\prime}\right)(h)=\Phi(g)\left(\Phi\left(g^{\prime}\right)(h)\right)$ for all $g, g^{\prime} \in G$ and $h \in H$.

An action $\Phi$ of $G$ on $H$ will also be required to have the property that $\Phi\left(1_{G}\right)=\mathrm{id}_{H}$, the identity mapping on $H$. Such an action is typically called a monoid action [5]. Thus, from this point on, an action will be a homomorphism $\Phi$ from $G$ to $\operatorname{Aut}(H)$.

In the case of abelian groups, the compatibility conditions can be simplified. The result is given in Proposition 2.2.

Proposition 2.2. [2] Let $G$ and $H$ be groups which act on each other and on themselves by conjugation. If $G$ and $H$ are abelian, then the mutual actions are compatible if and only if ${ }^{\left({ }^{g} h\right)} g^{\prime}={ }^{h} g^{\prime}$ and ${ }^{\left({ }^{h} g\right)} h^{\prime}={ }^{g} h^{\prime}$ for all $g, g^{\prime} \in G$ and $h, h^{\prime} \in H$.

In order to show that the actions of $G$ and $H$ on each other are compatible, it is suffices for the compatibility conditions to hold on the generators of $G$ and $H$. The general case was given by Vissher [5] and the following proposition focuses on the special case when both groups are cyclic and finite.

Proposition 2.3. Let $G=\left\langle x \mid x^{n}=1\right\rangle$ and $H=\left\langle y \mid y^{m}=1\right\rangle$ be finite cyclic groups of order $n$ and $m$, respectively. Furthermore, suppose $G$ and $H$ act on each other. If the compatibility conditions hold for $x$ and $y$, then the mutual actions are compatible.

If two actions act compatibly on each other, then there are some conditions which holds as stated in the following lemma. 
Lemma 2.4. [5] Let $G=\langle x\rangle, H=\langle y\rangle$ be cyclic groups. Furthermore let $G$ and $H$ act compatibly on each other so that ${ }^{y} x=x^{k}$ and ${ }^{x} y=y^{l}$. Then

$$
y^{l-1} x=x \text { and }{ }^{x^{k-1}} y=y \text {. }
$$

Next, the following proposition given is the general expansion formula for the nonabelian tensor products for finite cyclic groups where the proof can be found in [5].

Proposition 2.5. [5] Let $G=\langle x\rangle \cong C_{m}$ and $H=\langle y\rangle \cong C_{n}$ be finite cyclic groups which act nontrivially and compatibly on each other. Furthermore, let $k, l \in \mathbb{Z}$ with $0<k<m$ and $0<I<n$ such that ${ }^{y} x=x^{k}$ and ${ }^{x} y=y^{l}$. If $r, s \in \mathbb{Z}$ such that $0 \leq r<m$ and $0 \leq s<n$, then

$$
x^{r} \otimes y^{s}=(x \otimes y)^{\xi}\left(x^{k-1} \otimes y\right)^{\eta}
$$

where $\xi=s\left(\frac{I^{r}-1}{l-1}\right)$ and $\eta=\sum_{i=0}^{r-1} \sum_{j=0}^{s l^{i}-1} \frac{k^{j}-1}{k-1}$.

In the next section, we will give a new necessary and sufficient condition for a pair of cyclic groups of $p$-power order to act compatibly.

\subsection{COMPATIBLE ACTIONS FOR GYCLIC GROUPS OF $p$ - POWER ORDER}

In this section, compatible actions are investigated, in particular compatible actions between two cyclic groups of $p$-power order. We already have a necessary and sufficient condition for a pair of cyclic groups to act compatibly done by Visscher [5] but the condition does not consider the order of the action. Our new necessary and sufficient condition considers the order of the action and it is simpler than the existing condition.

The condition is stated in the following theorem. 
Theorem 3.1. Let $G=\langle g\rangle \cong C_{p^{\alpha}}$ and $H=\langle h\rangle \cong C_{p^{\beta}}$ where $\alpha, \beta \geq 2$. Furthermore, let $\sigma \in \operatorname{Aut}(G)$ with $|\sigma|=p^{k}$ where $k=1,2, \ldots, \alpha-1$ and $\sigma^{\prime} \in \operatorname{Aut}(H)$ with $\left|\sigma^{\prime}\right|=p^{k^{\prime}}$ where $k^{\prime}=1,2, \ldots, \beta-1$. Then $\left(\sigma, \sigma^{\prime}\right)$ is a compatible pair if and only if $k+k^{\prime} \leq \min \{\alpha, \beta\}$.

This theorem is useful in order to determine the pair of actions which is compatible.

\subsection{TENSOR PRODUCTS OF GYCLIC GROUPS OF ORDER $p^{2}, p$ AN ODD PRIME AND THE ACTIONS THAT HAVE ORDER $p$}

In this section, some of the nonabelian tensor products of cyclic groups of $p$ power order, $p$ an odd prime is shown to be cyclic. Some results in [5] are needed in order to proof the nonabelian tensor products of cyclic groups of order $p^{2}, p$ an odd prime and the actions that have order $p$ is cyclic.

By Proposition 2.5, clearly the tensor product is cyclic in our case if $x^{k-1} \otimes y \in\langle x \otimes y\rangle$. Thus, we need to show that $x^{p} \otimes y \in\langle x \otimes y\rangle$. We start with a few lemmas and corollaries.

Lemma 4.1. Let $G \cong H \cong C_{p^{2}}$ with $G=\langle x\rangle, H=\langle y\rangle, \quad p>2$, where ${ }^{x} y=y^{p+1}$ and ${ }^{y} x=x^{p+1}$. Then the actions are compatible and the following conditions hold:

$$
\begin{aligned}
& x^{p} y=y \text { and }{ }^{y^{p}} x=x, \\
& { }^{x} y^{p}=y^{p} \text { and }{ }^{y} x^{p}=x^{p} .
\end{aligned}
$$

Proof: Since ${ }^{x} y=y^{p+1}$ and ${ }^{y} x=x^{p+1}$, it follows by Lemma 2.4 that ${ }^{x^{p}} y=y$ and ${ }^{y^{p}} x=x$, and (3) holds.

To show (4), we observe

$$
{ }^{x} y^{p}=\left({ }^{x} y\right)^{p}=\left(y^{p+1}\right)^{p}=y^{p^{2}+p}=y^{p},
$$


and

$$
{ }^{y} \boldsymbol{X}^{p}=\left({ }^{y} \boldsymbol{X}\right)^{p}=\left(\boldsymbol{x}^{p+1}\right)^{p}=\boldsymbol{x}^{p^{2}+p}=\boldsymbol{x}^{p} .
$$

Hence (4) holds.

Lemma 4.2. Let $G \cong H \cong C_{p^{2}}$ with $G=\langle x\rangle, H=\langle y\rangle, p>2$, where ${ }^{x} y=y^{p+1}$ and ${ }^{y} x=x^{p+1}$. Then for all integers $k \geq 1$ we have

$$
\begin{aligned}
& \left(x^{k p} \otimes y\right)=\left(x^{p} \otimes y\right)^{k}, \\
& \left(x \otimes y^{k p}\right)=\left(x \otimes y^{p}\right)^{k} .
\end{aligned}
$$

Proof: The proof is by induction on $k$. The claim is obviously true for $k=1$. $\left(x^{1 \cdot p} \otimes y\right)=\left(x^{p} \otimes y\right)$. Now, assume it is true for some $k$ with $k \geq 1$, i.e. $\left(x^{k p} \otimes y\right)=\left(x^{p} \otimes y\right)^{k}$. Next, by Definition 1.2 and Lemma 4.1 we have

$$
\begin{aligned}
\left(x^{(k+1) p} \otimes y\right) & =\left(x^{p} x^{k p} \otimes y\right) \\
& =\left(x^{p} x^{k p} \otimes x^{x^{p}} y\right)\left(x^{p} \otimes y\right) \\
& =\left(x^{k p} \otimes y\right)\left(x^{p} \otimes y\right) \\
& =\left(x^{p} \otimes y\right)^{k}\left(x^{p} \otimes y\right) \\
& =\left(x^{p} \otimes y\right)^{k+1} .
\end{aligned}
$$

Thus, by the principle of mathematical induction, since (5) holds for $k+1$, then it follows that (5) holds for all positive integers $k$.

The proof of (6) follows in a similar manner.

Corollary 4.3. Let $G \cong H \cong C_{p^{2}}$ with $\left.G=\langle x\rangle, H=\langle y\rangle, \quad p\right\rangle 2$. If ${ }^{x} y=y^{p+1}$ and ${ }^{y} x=x^{p+1}$, then

$$
\begin{aligned}
& \left(x^{p} \otimes y\right)^{p}=\left(x \otimes y^{p}\right)^{p}=1_{\otimes}, \\
& \left(x \otimes y^{k_{1} p}\right)\left(x \otimes y^{k_{2} p}\right)=\left(x \otimes y^{\left(k_{1}+k_{2}\right) p}\right) .
\end{aligned}
$$

Proof: To show (7), by Lemma 4.2 for $k=p$, we have 


$$
\begin{aligned}
& 1_{\otimes}=\left(1_{G} \otimes y\right)=\left(x^{p^{2}} \otimes y\right)=\left(x^{p p} \otimes y\right)=\left(x^{p} \otimes y\right)^{p}, \\
& 1_{\otimes}=\left(x \otimes 1_{H}\right)=\left(x \otimes y^{p^{2}}\right)=\left(x \otimes y^{p p}\right)=\left(x \otimes y^{p}\right)^{p} .
\end{aligned}
$$

Thus (7) holds.

To prove (8), we observe that by (6) we have $\left(x \otimes y^{k_{1} p}\right)=\left(x \otimes y^{p}\right)^{k_{1}}$, $\left(x \otimes y^{k_{2} p}\right)=\left(x \otimes y^{p}\right)^{k_{2}}$ and $\left(x \otimes y^{\left(k_{1}+k_{2}\right) p}\right)=\left(x \otimes y^{p}\right)^{k_{1}+k_{2}}$. Then, our claim follows immediately.

Next we need another result, stated as follows.

Lemma 4.4. Let $G \cong H \cong C_{p^{2}}$ with $G=\langle x\rangle, H=\langle y\rangle$. If ${ }^{x} y=y^{p+1}$ and ${ }^{y} x_{x}=x^{p+1}$, then $x^{p} \otimes y=(x \otimes y)^{p}$.

Proof: We have $\left(x \otimes y^{(p+1)^{i}}\right)=x \otimes y^{i p+1}$ since $|y|=p^{2}$. Expanding by Definition 1.2 this yields

$$
\left(x^{p} \otimes y\right)=(x \otimes y)^{p} \prod_{i=1}^{p-1}\left(x \otimes y^{i p}\right) .
$$

By (8) we obtain

$$
\prod_{i=1}^{p-1}\left(x \otimes y^{i p}\right)=x \otimes y^{p} \cdot \sum_{i=1}^{p-1} i
$$

since $|y|=p^{2}$ and $p$ is odd. Our claim follows.

Next, we are ready to prove the nonabelian tensor products of cyclic groups of order $p^{2}, p$ an odd prime and the actions that have order $p$ is cyclic. We state the result in the following proposition.

Proposition 4.5. Let $G=\langle x\rangle, H=\langle y\rangle$ and $G \cong H \cong C_{p^{2}}$ with $p>2$. If $G$ and $H$ act on each other so that ${ }^{x} y=y^{p+1}$ and ${ }^{y} x=x^{p+1}$, then $G \otimes H$ is cyclic and $G \otimes H$ is a homomorphic image of $C_{p^{2}}$. 
Proof: By the definition of the nonabelian tensor product we have $G \otimes H=\left\langle x^{s} \otimes y^{t} \mid 0 \leq s, t \leq p-1\right\rangle$. To prove our claim, it suffices to show $x^{s} \otimes y^{t} \in\langle x \otimes y\rangle$. By Proposition 2.5 we have

$$
x^{s} \otimes y^{t}=(x \otimes y)^{\sigma}\left(x^{p} \otimes y\right)^{\tau}
$$

for integers $\sigma$ and $\tau$. However Lemma 4.4 yields $x^{p} \otimes y=(x \otimes y)^{p}$. Thus we conclude $x^{s} \otimes y^{t} \in\langle x \otimes y\rangle$. Observing that by Corollary 4.3 and Lemma 4.4 we have $1_{\otimes}=(x \otimes y)^{p^{2}}$. Since $G \otimes H=\langle x \otimes y\rangle$ and $|x \otimes y|$ divides $p^{2}$, our claim follows.

\subsection{SUMMARY AND CONCLUSION}

In this paper, we have given a necessary and sufficient condition for a pair of cyclic groups of $p$-power order to act compatibly on each other by considering the order of the actions. In addition, we have also proven that the nonabelian tensor products of cyclic groups of order $p^{2}, p$ an odd prime and the actions have order $p$ is cyclic.

\section{AGKNOWLEDGEMENT}

The authors would like to thank the Research Management Centre (RMC), Universiti Teknologi Malaysia, Johor Bahru for the financial funding through Fundamental Reseach Grant Scheme (FRGS) Vote 78481. The first author would also like to thank Universiti Malaysia Pahang (UMP) for his study leave and the Ministry of Higher Education (MOHE) Malaysia for the SLAI scholarship.

\section{REFERENCES}

[1] R. Brown, and J.-L. Loday. 1984. Excision Homotopique En Basse Dimension. C.R. Acad. Sci. Ser. I Math. Paris. 298: 353-356.

[2] R. Brown, and J.-L. Loday. 1987. Van Kampen Theorems for Diagrams of Spaces. Topology. 26: 311-335. 
[3] R. Brown, D. L. Johnson, and E. F. Robertson. 1987. Some Computations of Non-Abelian Tensor Products of Groups. Journal of Algebra. 111: 177-202.

[4] A. McDermott. 1998. The Nonabelian Tensor Product of Groups: Computations and Structural Results. PhD Dissertation. National University of Ireland, Galway.

[5] M. Visscher. 1998. On the Nonabelian Tensor Products of Groups. PhD Dissertation. State University of New York at Binghamton.

[6] G. Ellis. 1987. The Nonabelian Tensor Product of Finite Groups is Finite. J. Algebra. 11: 203-205. 